\title{
Play it safe or play to learn: mindsets and behavioral self-regulation in kindergarten
}

\author{
Miriam Compagnoni ${ }^{1}$ (D) $\cdot$ Yves Karlen $^{2} \cdot$ Katharina Maag Merki $^{1}$
}

Received: 29 November 2017 / Accepted: 15 March 2019 / Published online: 30 March 2019

(C) The Author(s) 2019

\begin{abstract}
Individuals hold different mindsets encompassing beliefs about trait stability (stable vs. malleable) and goal orientations (performance vs. mastery). These motivational beliefs affect behavioral self-regulation, which is an important predictor of school success and includes both executive functions (EF) and classroom behavioral self-regulation (CBSR). In this study, we examined the structure of mindsets in kindergarteners and the relations with EF and CBSR by interviewing 147 kindergarteners ( $51 \%$ female) aged 5 to 7 years $(M=6.47, \mathrm{SD}=.39)$. We used a multimethod approach with self-report and direct measures of behavioral self-regulation, achievement, and a newly developed mindset scale. Exploratory and confirmatory factor analyses revealed that trait beliefs and goal orientations represent two different but related motivational beliefs. Results indicated differential effects of trait beliefs and goal orientations on EF and CBSR: Children with a mastery (vs. performance) orientation showed better EF, whereas children with a belief in traits as malleable (vs. stable) showed better CBSR. Structural equation modeling showed significant indirect effects of both motivational beliefs on achievement, with EF and CBSR as mediators. Findings suggest that motivational beliefs are important in fostering behavioral self-regulation for successful adjustment to the demands of kindergarten.
\end{abstract}

Keywords Mindset · Goal orientation · Implicit theories · Executive functions · Behavioral selfregulation $\cdot$ Kindergarten

\section{Introduction}

Do some kindergarteners believe that their attributes (e.g., intelligence, abilities) are stable, like a set of predetermined strength and weaknesses, and do they therefore tend to seek out tasks

Miriam Compagnoni

mcompagnoni@ife.uzh.ch

1 Institute of Education, University of Zurich, Freiestrasse 36, 8032 Zurich, Switzerland

2 School of Education, University of Applied Sciences and Arts Northwestern Switzerland,

Bahnhofstrasse 6, 5210, Windisch, Switzerland 
that are easy for them to succeed at (fixed mindset)? Do other kindergarteners believe that their attributes are malleable and can be changed through effort and practice, and do they therefore tend to embrace challenges as learning opportunities (growth mindset)? The present study addresses these questions and explores the structure of growth and fixed mindsets in kindergarteners as well as the relation between these mindsets and behavioral self-regulation. Mindsets encompass two theoretically related motivational beliefs: trait beliefs, the belief that human attributes are stable or malleable, and goal orientations, the orientation towards mastery or performance goals (Gunderson et al. 2013; Dweck and Leggett 1988; for an overview, Dweck 2008). These two motivational beliefs (trait beliefs and goal orientations) might play an important role in explaining day-to-day behavioral self-regulation in kindergarten. Dweck and Leggett (1988) suggest a causal path that links trait belief to goal orientation and influences behavior in academic settings, but we know very little about the structure of mindsets in children under the age of 7 . There are findings that raise the question as to whether there even is a relation between trait beliefs and goal orientations (Spinath and Freiberger 2011; Kinlaw and Kurtz-Costes 2007). They might develop differently and have differential effects on classroom behavior (Gunderson et al. 2018). Taken together, it remains unclear if trait beliefs and goal orientations are interwoven into a growth or fixed mindset in kindergarteners and how they are related to behavioral self-regulation and achievement.

Process models of self-regulation imply a causal path between motivational beliefs, such as trait beliefs and goal orientations, and behavioral components, which in turn are connected again to motivational components via metacognitive processes in interactive cyclical phases (for an overview, see Panadero 2017). Self-regulation in kindergarten thus involves a dynamic interplay of motivational beliefs and behavior. But very little is known about mindsets and the unique contribution of young children's motivational beliefs (trait beliefs and goal orientations) in understanding behavioral self-regulation in kindergarten. Behavioral self-regulation has been described as a key predictor of successful adaptation to school and life (Blair and Raver 2015; Moffitt et al. 2013; Neuenschwander et al. 2012) and has been conceptualized as the ability to apply cognitive skills such as attention, working memory, and inhibitory control (Sektnan et al. 2010). Two distinct research directions have dealt with behavioral selfregulation as predictors of achievement: research on executive functions (EF), conceptualized as a basic domain-general construct, and context-specific research on higher order processes, such as classroom behavioral self-regulation (CBSR). But there is little overlap between the EF and CBSR literatures, and both of them rarely address the interaction with motivational beliefs.

Much of the research on EF stems from the field of cognitive neuroscience or neuropsychology and highlights that the training of inhibition, working memory, and cognitive flexibility in challenging situations is central to the development of executive functions (e.g. Moriguchi and Hiraki 2013; Kubesch and Hinte 2014; Bierman et al. 2008). The embracing of new challenging tasks is associated with a mastery orientation (Dweck and Leggett 1988), which might therefore play an important role in the development of EF. CBSR as higher order, context-specific processes that are supported by EF are more closely related to self-regulated behavior within academic contexts (Zimmerman and Kitsantas 2014), in which metacognitive reflection (Dignath and Buttner 2008) plays a central role. Laboratory and field studies with children have shown that a growth mindset is associated with childrens' metacognitive reflection, including enhanced attention to mistakes (Schroder et al. 2017) or adaptive reactions after setbacks (Schloz and Dresel 2011), which might play an important role in the development of CBSR.

To investigate these two research gaps regarding the structure of mindsets in young children as well as the relation with behavioral self-regulation and achievement, we conducted a study in 
kindergartens in Switzerland. In Swiss kindergartens the education of 4- to 6-year-olds is mostly interdisciplinary; play-focused learning and child-selected activities in a less structured environment is of great importance, and formal achievement feedback is rare, because formal reading, writing, and arithmetic generally begin in the first year of primary school at the age of 7 to 8 (Hauser 2013; EDK The Swiss Conference of Cantonal Ministers of Education 2017). We expected this context, in which children have great freedom in where, what, and with whom they want to play, to be particularly favorable for the development of differentiated mindsets, because it may provide, inter-individually, different opportunities for developing behavioral self-regulation (Ansari and Purtell 2017). Taken together, the aims of this study are to examine the structure of kindergarteners' mindsets (trait beliefs and goal orientations), the relations between mindsets and day-to-day behavioral self-regulation (CBSR and EF) and achievement and to potentially contribute to bridging the gap between theory and research on EF and CBSR.

\section{Mindsets in kindergarten: A composition of trait beliefs and goal orientation}

Mindsets fall under the broader construct of self-regulation as an umbrella term that includes the interaction of cognitive, metacognitive, behavioral, motivational, and emotional components (Panadero 2017). Mindsets (also called implicit theories) "set in motion a coherent system of beliefs, attributions, and attitudes toward challenges" (Gunderson et al. 2018, p. 397). For example, children with a growth mindset believe that traits are malleable, and they therefore adopt a mastery goal orientation to gain knowledge or skills, persist when they encounter challenging tasks, rebound better from occasional failures, and show better strategies after setbacks (Blackwell et al. 2007; Burnette et al. 2013; Diener and Dweck 1978; Hong et al. 1999; Schroder et al. 2017). In contrast, children with a fixed mindset believe that traits are stable, and they therefore adopt a performance goal orientation to demonstrate their abilities rather than put effort into improving abilities and are thus more likely to withdraw when challenges arise. Mindsets therefore unite two related motivational beliefs: trait beliefs and goal orientations, which affect behavioral self-regulation and achievement across diverse contexts (Dweck and Leggett 1988; Dweck 2008; Spinath and Freiberger 2011; Burnette et al. 2013). Some studies confirmed a relation between trait beliefs and goal orientations (Blackwell et al. 2007; Eccles and Wigfield 2002; for an overview see Dweck 2017), whereas others could not replicate it (Dupeyrat and Mariné 2005; Spinath 2001). In one of the only studies where mindsets were assessed in kindergarteners, Kinlaw and Kurtz-Costes (2007) found no support for the hypothesized relation between trait beliefs and goal orientations in kindergarteners but found a significant relation in 4th graders; they concluded that the two motivational beliefs are not yet interwoven into a growth or fixed mindset - although methodological issues due to the use of single items might have played a role. The structure and development of mindsets in young children therefore needs to be further evaluated, and we need to look more closely at the assessment of mindsets.

In the last decades a variety of different conceptual and methodological approaches has been reported to assess mindsets in young children, with various advantages and disadvantages. Because it remains unclear how and if trait beliefs and goal orientations are related, it seems problematic to use a composite measure, conceptualized as a multifaceted system of beliefs, including trait beliefs and goal orientations (Gunderson et al. 2013; Park et al. 2016), or to categorize children as having a growth or fixed mindsets based on their preference for a challenging or not challenging task (Smiley and Dweck 1994), or to induce mindsets through 
person or process praise (Mueller and Dweck 1998). The assessment of the two motivational beliefs separately with single items seems problematic as well (Kinlaw and Kurtz-Costes 2007). Although well-developed single-item measures might be appropriate in certain situations (Gardner et al. 1998), with young children, multiple item scales are necessary to ensure reliability. Schroder et al. (2017) assessed trait beliefs in children aged 6-8 years with 8 items similar to the ones used for adults, but they did not control for goal orientations and had to exclude 5-year-olds because they were not yet able to perform the task appropriately. The empirical database regarding the structure, distribution, and development of mindsets in children at this young age is therefore meager and inconclusive.

Although Dweck puts motivation and the formation of mindsets at the center of development from birth, she states that young children might have only an early form of the whole mindset framework, a belief in badness or goodness as fixed or malleable (Dweck 2017). Haimovitz and Dweck (2017a) see the development of mindsets as a result of socialization and changeable by various environmental influences but assume that they develop into a relatively stable trait that becomes more resistant to change with age (Robins and Pals 2002; Fryer and Elliot 2007). Feedback (Gunderson et al. 2013; Rattan et al. 2012; Dresel and Ziegler 2006; Mueller and Dweck 1998), teachers reference norm (Dickhäuser et al. 2017), or adults' reaction to mistakes (Haimovitz and Dweck 2017a) give learners clues that support the development of a corresponding mindset. For instance, Gunderson et al. (2013) showed that process praise given to toddlers predicted a growth mindset 5 years later. From a developmental and evolutionary psychological perspective, a strong mastery orientation can be expected in all young children, who have to develop new fundamental skills almost on a daily basis (e.g., walk, talk, learn to ride a bike). Young children are usually overoptimistic regarding their abilities and think that with effort they can master almost anything (Lipko et al. 2012; Hasselhorn 2005). Accordingly, some studies found indicators of a decline in the growth mindset during primary and middle-level school (e.g. Dickhäuser et al. 2017; Anderman et al. 2002), whereas other cross-sectional studies found no differences between kindergarteners and third graders (Kinlaw and Kurtz-Costes 2007) or even showed that 6-year-olds tended to endorse a belief in traits as more stable than older children did (Schroder et al. 2017) and that kindergarteners preferred easy tasks to be successful over difficult tasks to improve their skills (Kinlaw and Kurtz-Costes 2007). It might therefore be that developmental trajectories are not linear; there might be differential trajectories for trait beliefs and goal orientations as well as different trajectories interindividually. Contextual factors, such as feedback from significant others, performance indicators in the school system and classroom, and perceived task difficulty seem to play an important role and have to be taken into account when looking at the relation between motivational beliefs and behavioral self-regulation.

\section{Behavioral self-regulation: A composition of executive functions and classroom behavioral self-regulation}

Behavioral self-regulation also falls under the broader self-regulation construct (Sektnan et al. 2010), and includes skills such as "focusing and maintaining attention on tasks, following instructions, and inhibiting inappropriate actions" (Sektnan et al. 2010, p. 466). Various researchers see behavioral self-regulation skills as key predictors of success in school and life (Blair and Raver 2015; Cameron Ponitz et al. 2008; Garner 2009; Kubesch and Hinte 2014). In the early childhood research literature, a distinction can be made between domain-general behavioral self- 
regulation, such as executive functions $(\mathrm{EF})$, and context-specific behavior self-regulation, such as classroom behavioral self-regulation (CBSR) (Garner 2009; McClelland et al. 2007; Ursache et al. 2012). As a part of CBSR, children must actively remember instructions from the teacher (working memory), focus on the task at hand (attention), and ignore distractions (inhibition) in classrooms. EF refers to a similar set of skills and also includes several subcomponents, such as inhibition, cognitive shifting, attention, and working memory (e.g. Willoughby et al. 2016; Röthlisberger et al. 2010; Blair and Razza 2007). The subcomponents appear to gradually differentiate with age and often cannot be distinguished in young children (Moriguchi and Hiraki 2013). There is an ongoing debate on how to combine the scores on the subcomponents (Willoughby et al. 2016). Bull and Lee (2014) state that all behavioral self-regulation tasks draw on multiple underlying processes and are highly correlated in young children and that "independent contributions from updating, inhibition, and shifting may be seen only when differentiation is complete (i.e., late adolescence)" (p. 39).

Although EF and CBSR emerged from different fields, they are moderately related and share common theoretical, psychological, and neurological bases (Sektnan et al. 2010; Garner 2009). Some researchers use them synonymously, but researchers often describe them as overlapping and hierarchical, with EF as basic functions appearing to assist and support CBSR (Garner 2009; Ursache et al. 2012). Executive functions are strongly associated with activities in the prefrontal cortex, the part of the brain that undergoes huge developmental changes in childhood and is not fully developed until late adolescence (Moriguchi and Hiraki 2013). Training of inhibition, working memory, and cognitive flexibility in challenging situations seems to play a central role in the development of EF and the corresponding brain region (Moriguchi and Hiraki 2013; Bierman et al. 2008; Kubesch and Hinte 2014). EF are regularly investigated in young children, usually measured using behavioral or computer-based tasks in laboratory studies as predictors of achievement in the school context (Neuenschwander et al. 2012; Röthlisberger et al. 2010; Bull and Lee 2014), although the literature on EF seldom overlaps with literature on context-specific behavioral self-regulation. CBSR is described as a part of EF "that emerge from the interplay between early cognitive/brain development and environmental experiences" (Vernon-Feagans et al. 2016, p. 2). We therefore propose a hierarchical structure, with EF as a subordinate construct, conceptualized as a set of domain-general abilities that are correlated with and support CBSR as a higher order, context-specific developing skill set in kindergarten. CBSR is more closely related to self-regulated learning as a major framework that is used to understand students' learning within academic contexts (Zimmerman and Kitsantas 2014) and is often assessed on external observation measurement scales.

Based on previous research, a strong case can be made for the importance of both CBSR and EF for academic achievement (Gestsdottir et al. 2014; McClelland et al. 2007; von Suchodoletz et al. 2014), although mixed results emerge regarding the strength of the relation with achievement, depending on cultural context, measurement method, or domain. Children entering kindergarten already show individual differences in behavioral self-regulation, and practitioners as well as researchers are looking into what personal determinants might influence these differences.

\section{Mindsets, behavioral self-regulation, and achievement}

Interactions among personal determinants, such as mindsets, behavior, and environment have been described by Zimmerman (1989) within Bandura's social cognitive theory (Bandura and 
National Inst. of Mental Health 1986). Based on their work, Dweck and Leggett (1988) suggest a causal path that links mindsets to behavioral self-regulation. Links between mindsets and diverse aspects of behavioral self-regulation and achievement are well documented for children and adults (for an overview see Dweck 2008). Children with a growth (vs. fixed) mindset show more persistence after failure (Cain and Dweck 1995; Mueller and Dweck 1998; Stipek and Gralinski 1996), enhanced neuronal reaction to mistakes (Mangels et al. 2006), better goal monitoring and goal operation (Burnette et al. 2013), and better implementation of CBSR strategies when challenges arise (Schloz and Dresel 2011). A growth (vs. fixed) mindset has also been linked to better achievement in primary school (Park et al. 2016; Gunderson et al. 2018), but mainly when challenges arise (Hong et al. 1999; Schloz and Dresel 2011), or for academic underachievers (Paunesku et al. 2015). Meta-analytic results show only small effects for the relation between mindsets and achievement (Sisk et al. 2018); however, studies with kindergarteners are rare and are often conducted in the laboratory. Dweck and Leggett (1988) suggest a causal path from trait beliefs (stable vs. malleable) as relatively stable traits (Robins and Pals 2002) to achievement, via goal orientations (mastery vs. performance) and behavioral self-regulation as mediators of the relation, but on the basis of empirical research, it is often inconclusive whether the relation with behavioral self-regulation or achievement can be explained by goal orientations, stability beliefs, or an interaction of both. Additionally, the relation of these motivational beliefs to young children's' day-to-day behavior in classrooms remains understudied. The few studies on the topic with children under the age of 7 found that children aged 4-5 years with a preference for challenging tasks (vs. non challenging tasks) showed more persistence and mastery-oriented task choices during puzzle solving and a tower task (Smiley and Dweck 1994); children aged 6-8 years with malleable (vs. stable) trait beliefs showed enhanced neuronal attention to mistakes compared to children with a belief in stable abilities (Schroder et al. 2017); and in laboratory studies, children aged 4-7 years showed impaired behavioral self-regulation in different tasks after a fixed mindset has been induced through generic praise (Cimpian et al. 2007) or person praise (Kamins and Dweck 1999).

Goal orientations therefore seem to primarily influence task choice and persistence, with mastery-oriented children choosing difficult tasks for learning and performance-oriented children choosing easy tasks for demonstrating their abilities (Dweck and Leggett 1988). A mastery goal orientation should therefore lead to engagement in challenging tasks on a regular basis. These activities may strengthen EF directly (Vohs et al. 2012). But it remains uncertain if a mastery orientation leads directly to better CBSR in kindergarten or if it is mediated by better EF as the hierarchical model suggests (Raver et al. 2012). Choosing easy tasks to get it right may also benefit CBSR, especially in kindergarten, where children have to adapt to a new environment, social situation, and rules. Burnette et al. (2013) point out that the strategies hypothesized to be adopted by children with a mastery orientation are not always better or worse than those adopted by children with a performance orientation.

Trait beliefs, on the other hand, may be related to CBSR in kindergarten indirectly, as Dweck suggested, through goal orientations. A view of abilities as stable, therefore, should lead children to choose easier tasks and thus lead to fewer situations to train EF, which should indirectly affect CBSR. Based on recent empirical findings, another path seems possible: Trait beliefs seem to be especially sensitive to the perception of errors. Event-related potentials in a neural study show that children who believe that intelligence is malleable view errors as more motivationally relevant and expend more cognitive resources after mistakes on a go/no go task than children with a stable trait belief do (Schroder et al. 2017). Additionally, Haimovitz and Dweck (2017a) report that parents' beliefs about errors as motivating or demotivating, as well 
as their responses to their children's errors, predicted children's trait beliefs. Dignath and Buttner (2008) meta-analysis highlights the importance of metacogntive reflection in promoting strategy use in primary school. Malleable trait beliefs could therefore lead to better CBSR because errors and setbacks are seen as learning opportunities but could also be especially beneficial for children with a mastery goal orientation who chose difficult tasks and have to deal with failure on a daily basis. Children with a performance orientation, who are more likely to choose easy tasks, might therefore not benefit as much from a view of abilities as malleable, because they rarely encounter challenging tasks.

For young children, very little research has been conducted regarding the relation of mindsets and achievement. In a study by Gunderson et al. (2018), 2nd and 3rd graders' motivational beliefs predicted their 4th-grade math achievement and reading comprehension. When the researchers looked at the effect of process praise given to toddlers on achievement 7 years later, they found evidence that stability beliefs alone formed a link between parents' process praise and children's 4th grade achievement rather than goal orientation. Gunderson et al. suggest that "trait beliefs can form a powerful 'lens' through which children interpret and react to the challenges they encounter over time [...]. In contrast, children's reported learning goals may speak more specifically to their taste for challenge at the time and in the situation in which they report them" (p. 406). But the analyses did not include both motivational beliefs simultaneously, which makes it difficult to interpret the results. Other studies have shown that goal orientations mediate the relation between trait beliefs and achievement (Dickhauser et al. 2016).

In sum, mindsets appear to represent two motivational beliefs (see 'Mindsets in kindergarten' section above) that are both associated with behavioral self-regulation and achievement. However, the empirical evidence for the relation between trait beliefs and goal orientations as well as for the link to behavioral self-regulation and achievement is still very limited and somewhat inconsistent. The literature on EF is seldom combined with the literature on behavioral self-regulation in the academic context, motivational beliefs in children at this young age are rarely included, and possible differential effects have not been investigated. Overall, the structure of mindsets as well as the relation of trait beliefs and goal orientations with behavioral self-regulation remains unclear, especially in kindergarten, where developmental issues have to be taken into account and empirical research is scarce.

\section{Research questions and hypotheses}

We formed our questions and hypotheses considering unresolved issues in research on the structure of young children's mindsets and on the relation with behavioral self-regulation and achievement. Our research questions and hypotheses are:

1. Are trait beliefs and goal orientations interwoven into a growth or fixed mindset in kindergarten? Regarding the structure of mindset at this age, we expected trait beliefs and goal orientations to be separate but related factors $(\mathrm{H} 1)$.

2. Do trait beliefs and goal orientations have differing relations with EF and CBSR? Differential effects for trait beliefs and goal orientations on EF and CBSR were expected: Based on theoretical assumptions (Vohs et al. 2012), a mastery orientation in kindergarten should lead to the embracement of challenging tasks and is therefore hypothesized to be positively related to EF (H2a). Based on empirical findings regarding the different reactions to failure (Schroder et al. 2017), beliefs about traits as malleable are 
hypothesized to lead to better CBSR (H2b). Regarding the interaction of trait beliefs and goal orientations, we expected an indirect relation from trait beliefs to CBSR, with goal orientations and $\mathrm{EF}$ as mediators $(\mathrm{H} 2 \mathrm{c})$.

3. Are mindsets related to achievement? Regarding the interaction of mindsets with achievement, we assumed that there is an indirect relation, with self-regulated behavior as a mediator (H3).

\section{Methods}

\section{Participants}

Twenty secondary kindergarten classes in urban and rural areas were chosen to represent the demographic composition of the German-speaking part of Switzerland. In Switzerland, the vast majority of children enter kindergarten at the age of 4 to 5 and usually attend kindergarten for two years (primary and secondary kindergarten) in mixed age groups (EDK The Swiss Conference of Cantonal Ministers of Education 2017). In the permeable Swiss school system, skipping or repeating classes as well as early enrollment are commonplace.

For $91 \%$ of the children, we received parents and children's informed consent to participate, and refusals were due to unsystematic reasons (teacher informed only the day before the assessment, personal matters, and no reason given). Of these 153 kindergarteners, 147 children ( $51 \%$ female) aged 5 to 7 years $(M=6.47, \mathrm{SD}=.39)$ were included in the sample. Six children from the original sample were not included because of attentional deficits $(N=3)$ and selective mutism $(N=2)$; one child did not want to continue the interview $(N=1)$. Missings in the data were due to children who were ill at one of the two measuring times or technical network failures.

\section{Procedure}

The children were visited twice in the spring semester 2017 at their kindergartens, with an interval of 2-4 weeks between the assessments. Given the kindergarteners' lack of reading and writing skills, we used an individual-interview procedure to administer the tests. The mindset and behavioral self-regulation measures were administered in the context of a larger battery in a session that lasted approximately $25 \mathrm{~min}$. Mindsets were assessed at both visits and EF at visit two at the children's kindergarten in a quiet hallway or room. Teachers completed child self-regulated behavior and achievement ratings online between the two sessions.

\section{Measures}

Executive functions The new version of the Head-Toes-Knees-Shoulders Task (HTKS) was used as direct observational behavioral task to measure EF, as it measures the subcomponents working memory, attention, task switching, and inhibition (McClelland et al. 2014). As suggested by Bull and Lee (2014), we used a general measure, because independent contributions of subcomponents cannot be expected at this age (see also 'Behavioral self-regulation: a composition of EF and CBSR' section above). When compared to other commonly used EF tasks that measure subcomponents, the HTKS shows high construct validity and was significantly better at predicting growth in academic outcomes (McClelland et al. 2014). In the 
HTKS, the children were asked to play a game where they must do the opposite of what the experimenter says (if the experimenter instructed them to touch their toes (or their head), they had to touch their head instead). The first 10 items included two paired commands (head toes); the next 10 items added two new paired commands (shoulders - knees); and for the last 10 items, the four commands were paired differently than before. The children had to focus on the instructions and commands (attention), remember the paired rules (working memory), and stop a dominant response and replace it with the opposite response (inhibitory control). Each phase was introduced with practice items. Each of the 30 items was scored with 0 for an incorrect response, 1 for a self-correction, and 2 for a correct response. Total scores on the HTKS ranged from 2 to 57 points $(M=41.45, S D=11.05, \alpha=.89)$. Higher scores indicated higher levels of EF.

Classroom behavioral self-regulation The child behavior rating scale (Bronson et al. 1990) assesses behavioral self-regulation in the classroom, tapping also into different subcomponents of behavioral self-regulation (e.g., Concentrates when working (attention), returns to unfinished tasks after interruption (task switching, working memory), is not easily distracted (inhibition)). Previous studies have shown high construct and concurrent validity as well as internal consistency for the child behavior rating scale (Gestsdottir et al. 2014). The teacher rated each child on 10 items on a 5-point Likert scale from 1 (never) to 5 (always), where higher scores indicated higher levels of classroom behavioral self-regulation $(\mathrm{M}=3.81, \mathrm{SD}=.80, \alpha=.92)$.

Mindsets To assess growth and fixed mindsets, we used a self-report method (Fig. 1) based on the Berkeley Puppet Interview (Measelle et al. 1998) and included two scales, one for goal orientations (3 items; e.g., "I prefer to do very easy tasks that I'm good at.") and one for trait beliefs (4 items, e.g., "Yes, I think people can get smarter and smarter if they try."). The items were based on the subcomponents trait beliefs and goal orientations of the composite measure used by Gunderson et al. (2013) for children aged 7-8 years (see Appendix Table 4). The experimenter asked two identical plush elephant puppets placed left and right of a touchscreen standardized questions, and the children listened to the two puppets' answers delivered on the touchscreen; one puppet expressed a fixed mindset and the other a growth mindset. ${ }^{1}$ Combining the statements of puppets with a touch screen was motivating for the children, easy to administer, and has several advantages regarding objectivity, as the recorded statements of the two puppets are standardized, can be randomized, and can be listened to several times by the children themselves at the push of a button in case of comprehension problems (for further discussion of the tool, see the sections Limitations and Practical implications below). The children indicated on a semantic differential scale with 5 points, displayed between the puppets on the screen, whether they could identify with both or either one of the puppets a little or totally $(1=$ fixed to $5=$ growth). As suggested by Marsh et al. (2002), a double binary response strategy was used, where the identification with one puppet (by pressing a button) was always followed by a second probe ("Do you totally agree with this elephant or do you agree only a little?") to counter the tendency to push the endpoints and neglect the intermediate points.

Items were reverse-coded when necessary, so that a higher score was always associated with a more growth mindset. For some items, Z-values for kurtosis and skewness showed deviation from normality, with more children indicating a more growth mindset than a fixed mindset. A $\log$ transformation $(\ln (1+($ maximum $-\mathrm{x}))$ was performed on all mindset items to

${ }^{1}$ Many thanks to Jamie J. Jirout for her advice on scale development. 


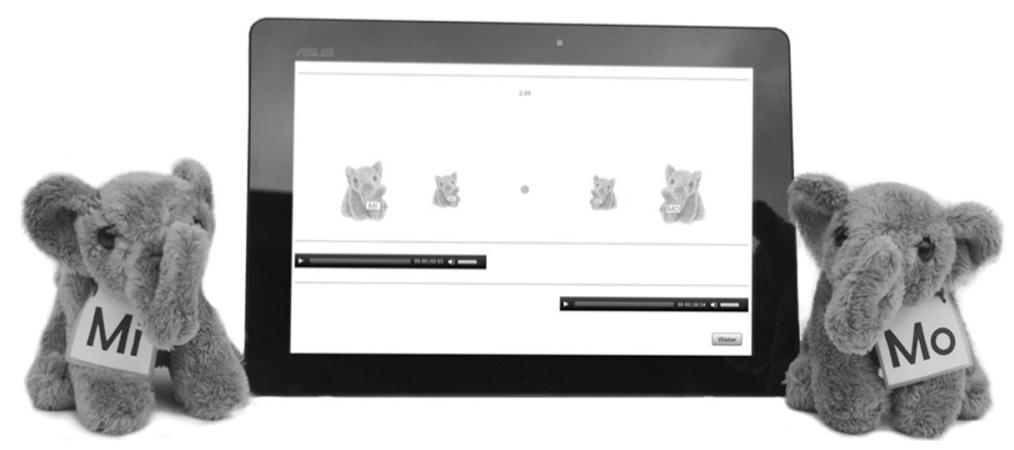

Fig. 1 A depiction of one item of the mindset measurement instrument

diminish distributional problems, although the data still remained left-skewed. In line with previous research on mindsets (Schloz and Dresel 2011; Gunderson et al. 2013), this was taken into account when selecting the methods for data evaluation. As our first research question concerned the structure of mindsets in kindergarteners, factor structure, descriptive statistics, and internal consistency are reported in the Results section below.

Achievement A teacher report measure was used to assess achievement in the pre-academic domains math and languages. Teachers had to rate each child's achievement for the language and math domain on a 9-point Likert scale (Cimeli et al. 2013). To enhance comparability and validity of the teacher reports, for each domain examples were listed (language: knowing letters, reading, writing; math: knowing numbers, arithmetic, and count). Because of the high correlation between the two measures, we aggregated them as a single achievement measure $(\mathrm{M}=6.62, \mathrm{SD}=2.04, \alpha=.84)$. Higher values indicated higher achievement.

\section{Results}

\section{Descriptive statistics}

Table 1 shows means, standard deviations, and range of behavioral self-regulation measures, achievement, and covariates. Table 2 shows zero-order rank correlations among all constructs.

\section{Structure of mindset}

To clarify the data structure of mindsets and to check for the assumed multidimensional structure of mindsets (H1) we conducted exploratory factor analysis (EFA). As hypothesized, EFA (Table 3) with oblimin rotation yielded a 2-factor solution $(54.32 \% \mathrm{EV})$, with acceptable item loadings from .59 to $.87 .^{2}$ The two factors, trait beliefs and goal orientations, showed a significant low correlation of $.23, p=.005$. To test the measurement models and to determine the factor structure of the data we applied confirmatory factor analyses (CFA). These procedures allowed us to compare a unidimensional model, representing mindsets as a composite measure including all mindset items, to a two-dimensional model with trait beliefs and goal

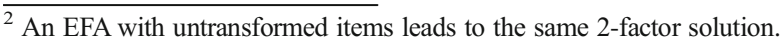


Table 1 Descriptive statistics: Behavioral self-regulation, achievement, gender, and age

\begin{tabular}{|c|c|c|c|}
\hline Variable & M & $\mathrm{SD}$ & Range \\
\hline \multicolumn{4}{|l|}{ Covariates } \\
\hline Age & 6.47 & .39 & $5.45-7.24$ \\
\hline Gender & \multicolumn{3}{|c|}{$1=$ Female: $52.4 \% 2=$ Male: $47.6 \%$} \\
\hline \multicolumn{4}{|l|}{ Behavioral self-regulation } \\
\hline Executive function (EF) a & 41.45 & 11.05 & $2-57$ \\
\hline Classroom behavioral self-regulation $(\mathrm{CBSR})^{\mathrm{b}}$ & 3.81 & .80 & $1.30-5.00$ \\
\hline Achievement & 6.20 & 2.04 & $1-9$ \\
\hline
\end{tabular}

${ }^{\mathrm{a}}=$ Head-Toes-Knees-Shoulders task

$\mathrm{b}=$ Child Behavior Rating Scale; $\mathrm{N}=147$

orientations computed as two separate but related factors. To compare the two models, we tested whether the $\chi 2$ statistics of both models differed significantly from each other. For this, the Satorra-Bentler scaled chi-square difference test (Satorra and Bentler 2010) was applied. We analyzed the data using Mplus 7.1 (Muthén and Muthén 1998-2016). For all analyses, parameters were estimated using maximum likelihood estimator with robust standard errors, which account for deviations from multivariate normality. The $\chi 2$ statistic, the comparative fit index (CFI), the root mean square error of approximation (RMSEA), and the standardized root mean square (SRMR) were used to evaluate model fit: RMSEA values smaller than .06, CFI values above .95, and SRMR values smaller than 0.08 are thought to indicate good model fit (Hu and Bentler 1999; Schermelleh-Engel et al. 2003). A CFA with two first-order latent factors immediately fit the data well $(\chi 2(13)=10.49, p=.653, \mathrm{RMSEA}=.000, \mathrm{CFI}=1.00$, SRMS =.034), in contrast to a model with one factor $(\chi 2(14)=31.04, p=.006$, RMSEA = $.091, \mathrm{CFI}=.87, \mathrm{SRMS}=.079)$, which fit the data significantly worse. The Satorra-Bentler scaled $\chi 2$ test revealed that the fit of the two-dimensional model was significantly different from the fit of the unidimensional model $(\Delta \times 2(1)=11.86, p<.001)$.

Given these findings, we constructed separate mindset scales for the two first-order factors. Goal orientations reflected the tendency to choose mastery or performance goals. The internal consistency for goal orientations was high $(\alpha=.87)$. Trait beliefs represented the belief that intelligence is more malleable or stable. The results matched previous findings, revealing low to moderate reliability in young children (Gunderson et al. 2018). The low reliability estimate of the trait beliefs scale $(\alpha=.51)$ is deemed sufficient for new scales, also for latent modeling in structural equation modeling (SEM) correcting for measurement error (Raines-Eudy 2000).

Table 2 Correlations among goal orientation, trait beliefs, executive functions, classroom behavioral selfregulation, gender, age, and achievement

\begin{tabular}{|c|c|c|c|c|c|}
\hline 1. $\mathrm{GO}$ & 2. TB & 3. EF & 4. CBSR & 5. Gender & 6. Age \\
\hline
\end{tabular}

1. Goal orientation (GO)

2. Trait beliefs (TB)

3. Executive functions (EF)

4. Classroom behavioral SR (CBSR)

\section{$-$}

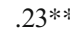

$.24 * *$

$.11 *$

$.18 * *$

$.16 *$

6. Age

7. Achievement

-
$.13 *$
$.18 * *$
$.14 *$
$-.05 * *$

$.22 * *$

$\begin{array}{ll}- & \\ .44 * * * & - \\ -.10 * & -.24 * * \\ .13 * & .17 * \\ .35 * * * & .63 * * *\end{array}$
.13
-.00

$N=137-142 ;$ Spearman's Rho; $* \mathrm{p}<.05 ; * * \mathrm{p}<.01 ; * * * \mathrm{p}<.001$; Goal orientation: higher values indicate a mastery orientation; Trait beliefs: higher values indicate a more malleable belief 
Table 3 Factor structure, internal consistency, and descriptives of mindsets in kindergarteners

\begin{tabular}{|c|c|c|}
\hline Items & Goal orientation & Trait belief \\
\hline Trait belief 1 & .225 & .408 \\
\hline Trait belief 2 & .238 & .551 \\
\hline Trait belief 3 & .167 & .803 \\
\hline Trait belief 4 & -.095 & .548 \\
\hline Goal orientation 1 & .798 & .096 \\
\hline Goal orientation 2 & .797 & .158 \\
\hline Goal orientation 3 & .795 & .180 \\
\hline Eigenvalue & 3.82 & 1.33 \\
\hline$\%$ Variance & 38.20 & 13.30 \\
\hline Cronbach's alpha & .87 & .51 \\
\hline $\mathrm{M}(\mathrm{SD})$ & $3.72(1.22)$ & $3.58(.90)$ \\
\hline$M(S D)^{a}$ & $1.38(.53)$ & $1.31(.40)$ \\
\hline
\end{tabular}

$\mathrm{N}=147$; Factor loadings $>.25$ are printed in bold; Rotation method: oblique rotation oblimin

a $=\log$-transformed items; for wording of the items, see appendix Table 4

Mean levels of mindset scales indicated that the children tended to be more mastery than performance oriented and believed that intelligence is more malleable than stable (Table 3).

\section{Relation between mindsets and behavioral self-regulation in kindergarten}

Our second research question addressed the differing relation of trait beliefs and goal orientations with EF and CBSR. Because of empirical studies reporting inconclusive results on age and gender differences in behavioral self-regulation and mindsets (Gunderson et al. 2013; Gestsdottir et al. 2014), gender and age were included as covariates. In our sample, boys scored significantly lower on CBSR and were more likely to adopt a mastery orientation than girls. Further, older children scored higher on CBSR and achievement than younger children (Table 2). To determine the proposed differential effects of goal orientations on EF (H2a) and of trait beliefs on CBSR ( $\mathrm{H} 2 \mathrm{~b}$ ), we performed two univariate variance analyses - one for EF and one for CBSR - and included gender and age as covariates. In the analysis with CBSR as a dependent variable, EF was introduced as a further control variable and, vice versa, CBSR for the analysis with EF as a dependent variable. Regarding their values in the two mindset variables, the kindergarteners were divided into two groups (mastery vs. performance goal orientation; malleable vs. stable trait belief) by means of median splits, ${ }^{3}$ to counter the leftskew data. The Levene test for both analyses was not significant $(\mathrm{CBSR}$ : $\mathrm{F}(3,135)=0.793$, $p=.500 ; \mathrm{EF}: \mathrm{F}(3,135)=0.860, p=.464)$, so that variance homogeneity can be assumed.

The analysis of variance for EF showed a significant main effect of goal orientation on EF with a medium effect size $(\mathrm{F}(1,132)=8.21, p=.005$, partial $\eta 2=.059, \mathrm{f}=.25)$, indicating that kindergarteners' executive functions vary depending on their goal orientation: Children with a mastery goal orientation showed higher $\mathrm{EF}(\mathrm{M}=43.68, \mathrm{SD}=1.23)$ than children with a performance goal orientation $(\mathrm{M}=38.74, \mathrm{SD}=1.20)$. For the trait beliefs factor, no major effect was apparent $(\mathrm{F}(1,132)=0.00, p=.998)$. The interaction term of trait beliefs and goal orientations on $\mathrm{EF}$ was not significant $(\mathrm{F}(1,132)=0.48, p=.827$, partial $\eta 2=.000)$. Thus, the relation of goal orientations with $\mathrm{EF}$ appeared to be independent of trait beliefs.

\footnotetext{
${ }^{3}$ To demonstrate the robustness of the effects, several statistical methods were calculated, including hierarchical regressions with continuous variables that yield the same significant main effects and no significant interactions.
} 


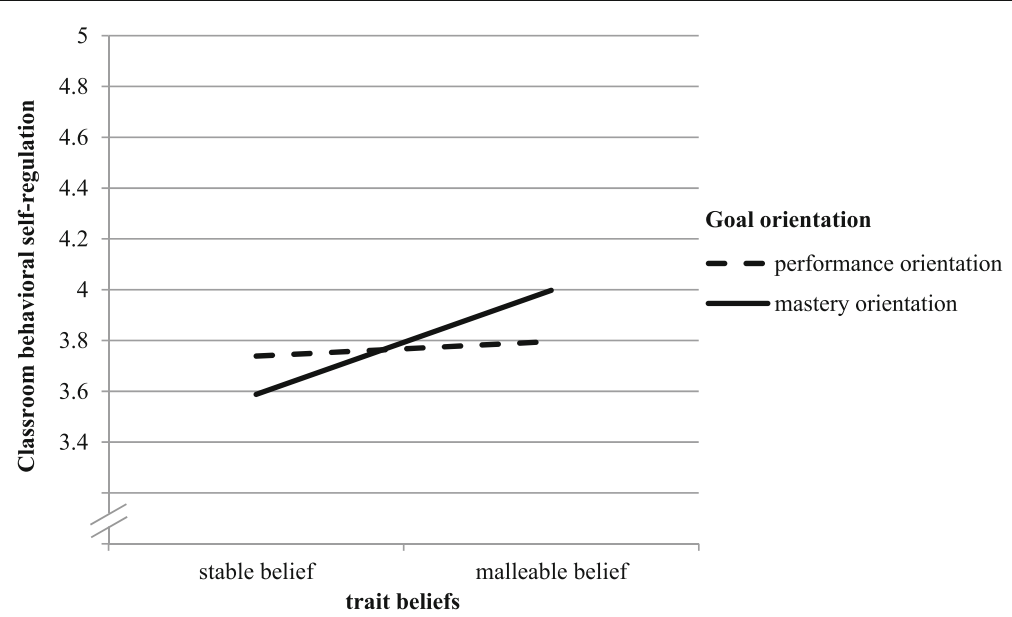

Fig. 2 Profile diagram for classroom behavioral self-regulation, with separate lines for goal orientation and beliefs about trait stability. $N=139$; Controlled for EF, gender, and age as covariates

The analysis of variance for CBSR showed a significant main effect of trait beliefs on CBSR with a small to medium effect size (Cohen 1992) $(\mathrm{F}(1,132)=4.67, p=.033$, partial $\eta 2=.034$, $\mathrm{f}=.19)$. This means that kindergarteners differ in their CBSR depending on their trait beliefs. CBSR was higher for children with a belief in traits as malleable $(\mathrm{M}=3.91, \mathrm{SD}=0.08)$ than stable $(\mathrm{M}=3.65, \mathrm{SD}=0.09)$. Results showed no significant main effect of goal orientation on CBSR $(\mathrm{F}(1,132)=0.72, p=.399)$. However, the interaction term of trait beliefs and goal orientation on CBSR showed a small effect size $(\mathrm{F}(1,132)=2.61, p=.11$, partial $\eta 2=.019$, $\mathrm{f}=.14$ ), indicating that children with a mastery orientation tended to show higher CBSR when they adopted a view of traits as malleable rather than a view of traits as stable (Fig. 2).

As outlined in the theoretical part, EF and CBSR follow a hierarchical logic. To test relations of mindsets to EF and CBSR simultaneously and have a closer look at possible interactions, in a second step we specified a linear structural equation model (see Fig. 3) using Mplus Version 7.1 (Muthén and Muthén 1998-2016). Trait beliefs and goal orientations were included as latent variables. Regarding missing data, the highest percentage of missing values at the item level was $4.8 \%$, and the lowest coverage was $92 \%$ of cases available to build the item covariance. As our data sets included missings, we estimated coefficients using the full information maximumlikelihood estimator with robust standard errors. This procedure allows the inclusion of cases with incomplete data. To estimate the proposed direct and indirect relations of trait beliefs and goal orientations with EF and CBSR (H2c), we conducted a SEM. ${ }^{4}$ Based on the theory-driven modeling, the measurement properties, few missing data, and our sample size with $n=147$, our model met the minimal assumptions regarding the ratio of free parameters per cases (Kline 2011). The model indices indicated immediately sufficient model fit $\left(\chi^{2}(23)=30.21, p=.144\right.$, $\mathrm{RMSEA}=.05, \mathrm{CFI}=.96, \mathrm{SRMR}=.05)$. Figure 3 shows the hypothesized model with goal orientations and EF as mediators of the relation between trait beliefs and CBSR (H2c) as well as the proposed differential relations of trait beliefs and goal orientations with CBSR and EF. The

\footnotetext{
${ }^{4}$ Although we argued above that gender is an important covariate, we were not able to include gender in the calculations for the SEM, because the number of free parameters would have been too large for our sample. If we run the analyses anyway, the model values for the SEM including gender indicated sufficient model fit $\left(\chi^{2}(28)=32.11, p=.270\right.$, RMSEA $=.03, \mathrm{CFI}=.98$, SRMR $\left.=.045\right)$ and the hypothesized differential relations of motivational beliefs with behavioral self-regulation remained.
} 

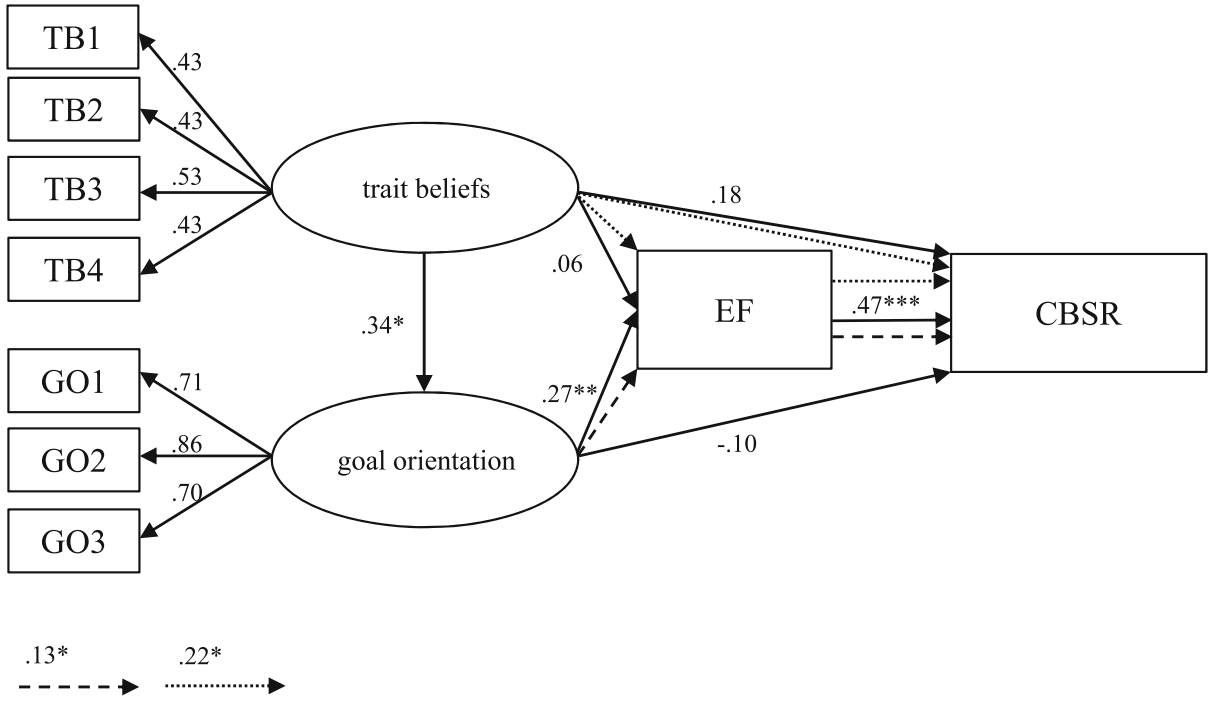

Fig. 3 Standardized SEM results for mindset and behavioral self-regulation. $N=147$; Standardized regression weights are presented with the significant paths in bold print. Indirect effects are presented with paths printed in dotted lines. $* \mathrm{p}<.05$, **p $<.01$, *** $\mathrm{p}<.001$, one-tailed. $\mathrm{TB}=$ trait beliefs; $\mathrm{GO}=$ goal orientation; $\mathrm{EF}=$ executive function; $\mathrm{CBRS}=$ classroom behavioral self-regulation

standardized regression weights revealed that goal orientation was significantly related to EF. The model showed no total or direct relation of goal orientations with CBSR, but there was a significant indirect relation via $\mathrm{EF}$ as a mediating variable $(\beta=.13, p=.017)$. A mastery orientation was therefore directly related with better $\mathrm{EF}$, but only indirectly over EF with better CBSR. Trait beliefs showed no significant direct relation with EF or CBSR, but there was a significant total effect of $\beta=.22(p=.034)$ which can be explained by a direct path to CBSR $(\beta=.18, p=.090)$ and an indirect path via goal orientation and $\mathrm{EF}$ on $\operatorname{CBSR}(\beta=.04, p=.075)$. The effect size of trait beliefs on goal orientations was medium, and EF was related significantly with CBSR with $\beta=.47$. Overall, standardized regression weights were small to medium in size.

\section{Interaction effects of mindsets and behavioral self-regulation in predicting achievement}

Correlation analyses showed that motivational beliefs, as well as behavioral self-regulation measures, were all positively correlated with achievement (Table 2). Path analysis was performed to test the suggested indirect paths through which motivational beliefs such as trait beliefs and goal orientations are associated with achievement (H3). Behavioral self-regulation, with $\mathrm{EF}$ as an underlying construct that affects CBSR, has been suggested as a mediator of the relation (see Fig. 3). To improve the number of free parameters to sample size ratio and to increase the stability of parameter estimates for this model, the use of manifest variables instead of latent variables was unavoidable (Kline 2011). We found immediately acceptable statistical fit indices for the model: $\chi^{2}(4)=4.29, p=.368$; RMSEA $=.02, \mathrm{CFI}=1.00, \mathrm{SRMR}=$ .033 . The relation between EF and achievement was fully mediated by CBSR. ${ }^{5}$ The total indirect relation of EF with achievement was $\beta=.29(p=.000)$, and there was no significant

\footnotetext{
${ }^{5}$ See also Table 2.
} 
direct relation $(\beta=.06, p=.458)$. The model showed the proposed indirect relations of mindsets with achievement via behavioral self-regulation (Fig. 4): The total indirect relation of goal orientations with achievement via EF and CBSR was $\beta=.10(p=.006)$. The total indirect relation of trait beliefs with achievement via goal orientations, EF, and CBSR was $\beta=$ $.12(p=.005)$ and therefore predicted $12 \%$ of the variance in children's achievement.

\section{Discussion}

Mindsets create a motivational framework that encompasses the belief in traits as either malleable or stable and the orientation toward mastery or performance goals. These two motivational beliefs (trait beliefs and goal orientations) might play an important role in explaining day-to-day behavioral self-regulation in kindergarten. Behavioral self-regulation is widely recognized as an important predictor in early childhood for later successes in school and life (Blair and Raver 2015; Moffitt et al. 2013). But research on EF has often been kept separate from context-specific research on classroom behavioral self-regulation and has rarely been put in relation to motivational beliefs - especially in children this young. Overall, our findings indicate that trait beliefs and goal orientations are not strongly interwoven in a coherent framework of growth and fixed mindsets in kindergarteners (research question 1) and that both of these motivational beliefs are related to day-to-day behavioral self-regulation in kindergarten. But there is a differential relationship between kindergarteners' trait beliefs and goal orientations and EF and CBSR (research question 2). In addition, we evaluated the interaction of mindsets, behavioral self-regulation, and achievement in kindergarteners, and our findings indicate that motivational beliefs are related to achievement through behavioral selfregulation as a mediator (research question 3).

Our first question addressed the structure of mindsets. According to Dweck and Leggett (1988), mindsets encompass trait beliefs and goal orientations. These two motivational beliefs have often been combined in composite measures of mindsets in children (Gunderson et al. 2013;

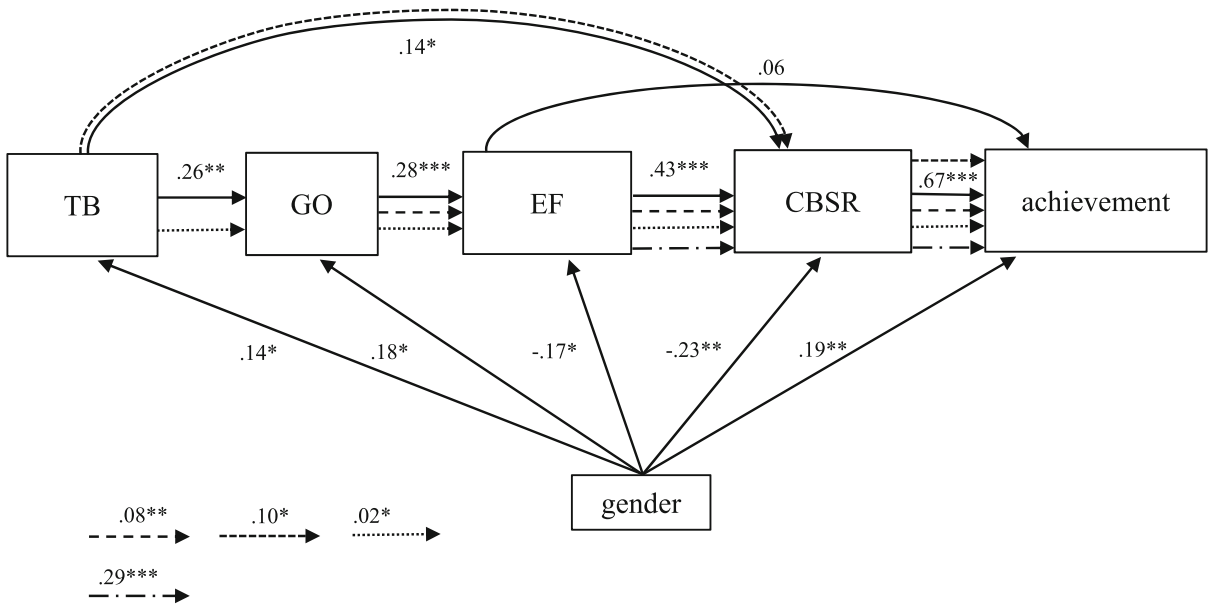

Fig. 4 Standardized solution for the mindset-self-regulation achievement model. $N=147$; Standardized regression weights are presented with the significant paths in bold print. Indirect effects are presented in paths printed with dotted lines. $* \mathrm{p}<.05$, **p $<.01$, *** $\mathrm{p}<.001$, one-tailed. $\mathrm{TB}=$ trait beliefs; $\mathrm{GO}=$ goal orientation; $\mathrm{EF}=$ executive function; $\mathrm{CBRS}=$ classroom behavioral self-regulation 
Park et al. 2016). For the present sample, a two-factorial structure was confirmed, with small to medium correlations between the two motivational beliefs (H1). Although trait beliefs and goal orientations are related, they do not form a coherent framework of growth and fixed mindsets in kindergarteners. Based on Kinlaw and Kurtz-Costes (2007) findings, it can be assumed that the relation may intensify when children proceed through middle childhood, as theory construction then becomes more internally consistent, although some researchers question the assumption that goal orientations are related to trait beliefs even in primary school (Spinath and Freiberger 2011). Since previous research has hardly focused on the development of mindsets in children this young, and if so, then only by means of cross-sectional data, there is an urgent need for longitudinal studies to learn more about the interaction and development of these highly relevant motivational beliefs in learning contexts. In line with developmental psychological findings, our results confirm that kindergarteners tend to believe that traits are more malleable than stable, and the children have a tendency towards a mastery versus a performance orientation. It might be that developmental trajectories are not linear and differ for trait beliefs and goal orientations as separate motivational beliefs. It has been suggested that children's goal orientations may be more of an indicator of their taste for challenges in the specific academic situation (Gunderson et al. 2018) and may be highly dependent on goal orientations that are stressed in their classrooms (Anderman et al. 2002). For example, at the beginning of kindergarten, praise for successful solving of easy tasks might be common and might promote a performance orientation (Nicholls 1978), whereas during kindergarten and the first years of primary school, praise for successful performing of difficult tasks might lead to a mastery goal orientation. But with children's increasing age, the pressure to get high grades to get into desired school tracks increases and might lead again towards a performance orientation (Haimovitz and Dweck 2017b). Trait beliefs, on the other hand, might be more dependent on how the environment reacts to failure (Haimovitz and Dweck 2017a) and how strongly human attributes are associated with different social groups (Cimpian et al. 2012). For instance, the strong gender rigidity in kindergarten (Blossfeld et al. 2009) might lead to a view of abilities as stable that gets more malleable with age. The increasing pressure from parents and society to get into desired school tracks or to choose a desired profession might lead to a view of abilities as more stable with increasing age when test results and failure might be seen as a measure of their talents, strengths, and weaknesses and not their actual skills (Haimovitz and Dweck 2017b). Future studies will have to look into interindividual and intraindividual developmental trajectories of trait beliefs and goal orientations as separate but interdependent motivational beliefs.

Our second question addressed the relation between motivational beliefs and behavioral selfregulation. Results support the assumption that motivational beliefs in kindergarten are related to day-to-day behavioral self-regulation. We assumed in $\mathrm{H} 2$ differential effects of trait beliefs and goal orientations on EF and CBSR. Kindergarteners with a mastery goal orientation, regardless of their trait beliefs, show better executive functions than children with a performance orientation ( $\mathrm{H} 2 \mathrm{a})$ do, which is related indirectly $(\mathrm{H} 2 \mathrm{c})$ to better behavioral selfregulation in the classroom (see Fig. 3). This seems to confirm the assumption that working on difficult tasks in kindergarten might lead to activities that strengthen basic domain-general EF, such as impulse control, directly (Vohs et al. 2012), and this is reflected in better higher order processes such as CBSR only indirectly. Higher EF seems to aid self-regulated behavior in classrooms by allowing kindergarteners to engage in well-planned, flexible, goal-oriented behavior. However, due to the cross-sectional data, it cannot be ruled out that high EFs may also lead children to choose rather difficult tasks - perhaps because they are confident that they can handle it. 
In accordance with our hypotheses (H2b), children who believe in the malleability of their traits show better behavioral self-regulation in the classroom than children with a stable view (see analysis of variance). The relation with CBSR can be explained mainly through a direct path and only a week indirect path through goal orientations and EF (see Fig. 3). For the relation between trait beliefs and CBSR, goal orientations and EF play only a minor role. Hypothesis $2 \mathrm{c}$ can therefore only be partly supported. But the direct path seems to confirm the assumption that complex higher order processes, such as behavioral self-regulation in the classroom, might benefit from a view of one's intelligence as malleable. Based on previous research, a possible explanation for this relation might be the better metacognitive reflection after mistakes (Schroder et al. 2017; Schloz and Dresel 2011). Further, the results indicate that a view of traits as malleable might be especially beneficial for children with a mastery orientation (see Fig. 2). As recent research suggests, trait beliefs seem to be especially beneficial for achievement when dealing with failure (Schroder et al. 2017), which would be less common for children who adopt a performance orientation and choose easy tasks in kindergarten. Other mediators might play a role, such as ability self-concept (Schloz and Dresel 2011), stereotype threat (Cimpian et al. 2012), or attention to mistakes (Schroder et al. 2017) and have to be addressed in future research.

This study based on a conceptual distinction between domain-general EF and CBSR as part of behavioral self-regulation in kindergarten (Garner 2009; Ursache et al. 2012). The results support the proposed hierarchical structure of behavioral self-regulation, with EF as a basic domain-general underlying construct that assists and supports behavioral self-regulation in the classroom. In line with previous research (McClelland et al. 2014), our findings confirm that children with higher EF and better CBSR show better achievement in kindergarten. Behavioral self-regulation is one of the most important precursors of achievement, and the role of motivational beliefs in supporting behavioral self-regulation and achievment is of high interest. However, meta-analytic average correlation between trait beliefs and achievement is very weak (Sisk et al. 2018). But research has found that mindsets are mainly related to achievement when challenges arise and success is difficult, e.g., for students with low socioeconomic status or students who are academically at risk (Blackwell et al. 2007; Sisk et al. 2018). Therefore, behavioral self-regulation might be the mediating factor between mindsets and achievement. The results of this study support our hypothesis (H3) that mindsets are related to achievement via EF and CBSR as mediators. As could be expected from previous analyses, a mastery orientation is related primarily to achievement through better EF, which in turn is related to CBSR. Beliefs in traits as malleable seem to be positively related to achievement in more complex ways: directly via better CBSR and indirectly via a mastery orientation, which is related to better EF and CBSR. But why did we even expect to find a relation of mindsets with achievement in kindergarten - which is a supportive, possibly less challenging environment than primary school, which is more achievement-oriented? It may be that kindergarten provides more of a 'growth environment' than elementary school does. In Swiss kindergartens, where children devote a large part of their time to free play, a mastery orientation and a view of abilities as malleable might be especially beneficial for behavioral self-regulation and achievement, whereas a performance orientation and a fixed view might lead children to play often in the same play center and to choose tasks that they have already mastered. In the more fixed environment of primary school, where a temporal reference norm might be less common, students are constantly graded, often separated into achievement groups, praised for flawless performance, and teacher-directed activity settings are more common; a performance orientation and a belief in fixed traits could also prove beneficial for achievement (Dickhäuser et al. 
2017; Dweck 2017; Haimovitz and Dweck 2017b). Future studies will have to take a closer look at developmental trajectories of trait beliefs and goal orientations and the relation with behavioral self-regulation within the context of schools and classes.

This study contribute to bridging the gap between the literature on EF and classroom behavioral self-regulation. Based on our results, it might be fruitful for research and theory concerned with the relation of motivational beliefs and behavioral self-regulation to differentiate between trait beliefs and goal orientations and between executive function and classroom behavioral self-regulation. This might help us to gain further insights into the interplay of trait beliefs and goal orientations in relation to behavioral self-regulation and achievement.

\section{Limitations and research implications}

Although the results indicate significant relations between mindsets, behavioral self-regulation, and academic achievement, several limitations should be noted. As the results are correlational, no causal effects could be analyzed. The results build on previous experimental and theoretical work that established a causal link between mindsets and behavioral outcomes; experimental designs and longitudinal data would be preferable to measure the predictive value of mindsets on behavioral self-regulation and achievement.

Regarding measurement issues, there are several things to be noted. Although the internal consistency of the newly developed scale on trait beliefs is sufficient for our analyses, and the relations with behavioral self-regulation and goal orientations were as expected, future studies should develop and add new items (e.g., domain-specific items), and the scales should be compared with other measures to improve the internal consistency and validity of the scales. For transfer into other contexts, it seems important to choose the words used very carefully. Gschid, the Swiss German word for smart or intelligent, might mean different things when translated into other cultures and languages. One could also argue that individually different perceptions of the word chosen pose a problem for the validity of the scale. However, we see it that different perceptions of the word are expressions of different mindsets. Although children could easily decide on one statement, their comments show that they identify strongly with the puppets, e.g., "Sorry Elephant, I like you too, but I think this time the other one is right" or "I think both are a little right." It therefore seems crucial to choose two identical, gender-neutral puppets and to randomize the answers, as we did here.

Another limitation of this study is the sample size, which did not allow us to model a more complex latent SEM. Although mean value comparisons with median splits reinforce our findings, future studies should replicate our SEM results with larger samples to ensure that significant effects not have been overstated. Inferential statistic results are always subject to a certain degree of uncertainty. We also used a plurality of measurement approaches to assess behavioral self-regulation, but all measures have limitations. Teacher ratings are closer to context-specific behavior that occurs in natural settings but are also more susceptible to rater bias than direct measures. The high relation of CBSR with achievement in kindergarten can be partly explained by the fact that both measures were assessed by teacher ratings, although measured on completely different scales. Therefore, we encourage researchers to include different aspects of behavioral self-regulation as well as different measures of mindsets and achievement in future studies. Other factors that might influence the relationship should also be considered in future research, such as socioeconomic status (Paunesku et al. 2015), epistemological beliefs (Chen and Pajares 2010), ability self-concept (Schloz and Dresel 2011), or differential reaction to failure (Dresel et al. 2013). 


\section{Practical implications}

Given the sparse findings on kindergarten children's motivational beliefs in relation to behavioral self-regulation up to now, this study provides researchers and practitioners with new and interesting insights into the belief system of kindergarteners. Our results suggest that already in kindergarten, fostering a growth mindset could prove beneficial for behavioral selfregulation. Fostering a mastery orientation might lead children to embrace challenges, deal with setbacks, and therefore learn to regulate their bottom-up emotions and train higher-order processes such as EF. Kindergarten teachers should provide a learning environment where choosing new or challenging tasks and play centers, making mistakes, failing, and learning are commonplace, so that children see mistakes not as harmful but as an important way to learn. A child's repetitive play undoubtedly has its own educational value, but teachers should be sensitized to see this not uncritically as due not only to the child's interest, talent, or natural tendencies, as it may be a sign of a performance orientation that might impair the development of EF if challenges are avoided. But Diamond and Lee (2011) also emphasize that the best approach to improve behavioral self-regulation may be to engage children's passionate interests, which brings them joy and pride. Fostering a belief in traits as malleable might support behavioral self-regulation in classrooms, partly through a mastery orientation and therefore better EF, but also through adequate attention and reactions to errors and setbacks. A variety of actions have been proposed on how teachers can try to modulate a growth learning environment: praising the process instead of the person, e.g., "You build this tower very carefully!" instead of "You are a very talented builder!" (Cimpian et al. 2012; Mueller and Dweck 1998); adopting a temporal reference norm orientation, e.g., giving feedback based on individuals' previous performance (Dickhäuser et al. 2017) or viewing failures as enhancing, e.g., not praising flawless work but praising the learning process after failures (Haimovitz and Dweck 2017a). Although a variety of interventions are implemented to foster a growth mindset, it is often not possible to untangle whether the proposed actions target trait beliefs or goal orientations or both. Future research should look deeper into the development, context sensitivity, structure, and stability of growth and fixed mindsets and the contextual factors that shape children's mindsets. Motivational beliefs might be a small part of fostering behavioral self-regulation in kindergarteners but help increase the probability that children will enter first grade with the behavioral self-regulatory skills that they need.

Despite some limitations, this study conveys an important and hopeful message: Encouraging a mastery goal orientation in children might help them to embrace challenges and persist when difficulties arise and therefore train their EF. Fostering a belief in human attributes as malleable might help children to see that mistakes do not mean that they are incompetent but are the only way to better self-regulate their learning in kindergarten. Kindergarten seems to be a good starting point for educators to cultivate the seeds of a growth mindset and help children to not 'play it safe' but to play to learn and learn for life.

Compliance with ethical standards All procedures followed were in accordance with the ethical standards of the responsible committee (The Ethics Committee of the Faculty of Arts and Social Sciences, University of Zurich). Informed consent was obtained from all participants for being included in the study. Children were informed in an age appropriate manner and signed a consent form. Parents received written information and signed the consent form.

Conflict of interest The authors declare that they have no conflict of interest. 


\section{Appendix}

Table 4 Items on the mindset scales: Mean, standard deviation, and range of the untransformed items on the mindset scales

\begin{tabular}{|c|c|c|c|c|}
\hline \multicolumn{2}{|l|}{ Variable } & \multirow{2}{*}{$M$} & \multirow{2}{*}{ SD } & \multirow{2}{*}{ Range } \\
\hline TB1 (A): & $\begin{array}{l}\text { Can people change how smart they are? } \\
\text { Yes, I think people can get smarter and smarter if they try. (growth) } \\
\text { No, I think people stay pretty much the same. (fixed) }\end{array}$ & & & \\
\hline TB2 (A): & $\begin{array}{l}\text { Why are some kids smarter than the others?* } \\
\text { That's just how it is. (fixed) } \\
\text { It is because they worked really hard. (growth) }\end{array}$ & 3.27 & 1.55 & $1-5$ \\
\hline TB3 (B): & $\begin{array}{l}\text { Can children change how smart they are?* } \\
\text { No, I think they stay pretty much the same. (fixed) } \\
\text { Yes, I think people can get smarter and smarter if they try. (growth) }\end{array}$ & 3.87 & 1.35 & $1-5$ \\
\hline TB4 (B): & $\begin{array}{l}\text { Why are some people smarter than the others? } \\
\text { It is because they worked really hard. (growth) } \\
\text { That's just how it is. (fixed) }\end{array}$ & 3.22 & 1.46 & $1-5$ \\
\hline GO1 (B): & $\begin{array}{l}\text { What do you prefer in kindergarten - easy or hard tasks?* } \\
\text { I prefer to do very easy tasks that I'm good at. (fixed) } \\
\text { I prefer to do very hard tasks so I can get better. (growth) }\end{array}$ & 3.81 & 1.39 & $1-5$ \\
\hline GO2 (B): & $\begin{array}{l}\text { Do you like to do tasks with numbers that are very hard so } \\
\text { you can learn more about numbers or very easy so you } \\
\text { can get a lot right?* } \\
\text { I prefer very easy tasks. (fixed) } \\
\text { I prefer very hard tasks. (growth) }\end{array}$ & 3.71 & 1.43 & $1-5$ \\
\hline GO3 (B): & $\begin{array}{l}\text { Do you like to do very hard tasks with letters so you can get a } \\
\text { lot right or very easy tasks so you can learn more about letters? } \\
\text { I prefer very hard tasks. (growth) } \\
\text { I prefer very easy tasks. (fixed) }\end{array}$ & 3.65 & 1.51 & $1-5$ \\
\hline
\end{tabular}

$\mathrm{TB}=$ trait belief; $\mathrm{GO}=$ goal orientation. Items marked 'A' were presented at the first session, and items marked 'B' were presented at the second session. Items marked with an asterisk $\left(^{*}\right)$ were reverse-coded, so that higher scores were always associated with greater endorsement of a growth orientation. The items shown here have been translated from Swiss German

Open Access This article is distributed under the terms of the Creative Commons Attribution 4.0 International License (http://creativecommons.org/licenses/by/4.0/), which permits unrestricted use, distribution, and reproduction in any medium, provided you give appropriate credit to the original author(s) and the source, provide a link to the Creative Commons license, and indicate if changes were made.

\section{References}

Anderman, E. M., Austin, C. C., \& Johnson, D. M. (2002). Chapter 8 - the development of goal orientation. In A. Wigfield \& J. S. Eccles (Eds.), Development of achievement motivation (pp. 197-220). San Diego: Academic Press.

Ansari, A., \& Purtell, K. M. (2017). Activity settings in full-day kindergarten classrooms and children's early learning. Early Childhood Research Quarterly, 38, 23-32. https://doi.org/10.1016/j.ecresq.2016.09.003.

Bandura, A., \& National Inst. of Mental Health. (1986). Prentice-Hall series in social learning theory. In Social foundations of thought and action: A social cognitive theory. Englewood Cliffs: Prentice-Hall.

Bierman, K. L., Nix, R. L., Greenberg, M. T., Blair, C., \& Domitrovich, C. E. (2008). Executive functions and school readiness intervention: Impact, moderation, and mediation in the head start REDI program. Development and Psychopathology, 20(3), 821-843. https://doi.org/10.1017/S0954579408000394.

Blackwell, L., Trzesniewski, K., \& Dweck, C. S. (2007). Implicit theories of intelligence predict achievement across an adolescent transition: A longitudinal study and an intervention. Child Development, 78(1), 246263. https://doi.org/10.1111/j.1467-8624.2007.00995.x. 
Blair, C., \& Raver, C. C. (2015). School readiness and self-regulation: A developmental psychobiological approach. Annual Review of Psychology, 66, 711-731. https://doi.org/10.1146/annurev-psych-010814015221.

Blair, C., \& Razza, R. P. (2007). Relating effortful control, executive function, and false belief understanding to emerging math and literacy ability in kindergarten. Child Development, 78(2), 647-663. https://doi. org/10.1111/j.1467-8624.2007.01019.x.

Blossfeld, H.-P., Bos, W., Hannover, B., Lenzen, D., Müller-Böling, D., Prenzen, M., et al. (2009). Geschlechterdifferenzen im Bildungssystem. München: VS Verlag für Sozialwissenschaft.

Bronson, M. B., Goodson, B. D., Layzer, J. I., \& Love, J. M. (1990). Child behavior rating scale. Cambridge: Abt Associates.

Bull, R., \& Lee, K. (2014). Executive functioning and mathematics achievement. Child Development Perspectives, 8(1), 36-41. https://doi.org/10.1111/cdep.12059.

Burnette, J. L., O'Boyle, E. H., VanEpps, E. M., Pollack, J. M., \& Finkel, E. J. (2013). Mind-sets matter: A metaanalytic review of implicit theories and self-regulation. Psychological Bulletin, 139(3), 655-701. https://oi. org/10.1037/A0029531.

Cain, K. M., \& Dweck, C. S. (1995). The relation between motivational patterns and achievement cognitions through the elementary-school years. Merrill-Palmer Quarterly, 41(1), 25-52.

Cameron Ponitz, C. E., McClelland, M. M., Jewkes, A. M., Connor, C. M., Farris, C. L., \& Morrison, F. J. (2008). Touch your toes! Developing a direct measure of behavioral regulation in early childhood. Early Childhood Research Quarterly, 23(2), 141-158. https://doi.org/10.1016/j.ecresq.2007.01.004.

Chen, J. A., \& Pajares, F. (2010). Implicit theories of ability of grade 6 science students: Relation to epistemological beliefs and academic motivation and achievement in science. Contemporary Educational Psychology, 35(1), 75-87. https://doi.org/10.1016/j.cedpsych.2009.10.003.

Cimeli, P., Neuenschwander, R., Röthlisberger, M., \& Roebers, C. M. (2013). Das Selbstkonzept von Kindern in der Schuleingangsphase. Zeitschrift Fur Entwicklungspsychologie Und Padagogische Psychologie, 45(1), 1-13. https://doi.org/10.1026/0049-8637/a000075.

Cimpian, A., Arce, H. M. C., Markman, E. M., \& Dweck, C. S. (2007). Suble linguistic cues impact children's motivation. Psychological Science, 18(4), 314-316. https://doi.org/10.1111/j.1467-9280.2007.01896.x.

Cimpian, A., Mu, Y., \& Erickson, L. C. (2012). Who is Good at this game? Linking an activity to a social category undermines Children's achievement. Psychological Science, 23(5), 533-541. https://doi. org/10.1177/0956797611429803.

Cohen, J. (1992). A power primer. Psychological Bulletin, 112(1), 155-159. https://doi.org/10.1037/00332909.112.1.155.

Diamond, A., \& Lee, K. (2011). Interventions shown to aid executive function development in children 4 to 12 years old. Science, 333(6045), 959-964. https://doi.org/10.1126/science.1204529.

Dickhauser, O., Dinger, F. C., Janke, S., Spinath, B., \& Steinmayr, R. (2016). A prospective correlational analysis of achievement goals as mediating constructs linking distal motivational dispositions to intrinsic motivation and academic achievement. Learning and Individual Differences, 50, 30-41. https://doi.org/10.1016/j. lindif.2016.06.020.

Dickhäuser, O., Janke, S., Praetorius, A.-K., \& Dresel, M. (2017). The effects of teachers' reference norm orientations on students' implicit theories and academic self-concepts. Zeitschrift Fur Padagogische Psychologie, 31(3-4), 205-219. https://doi.org/10.1024/1010-0652/a000208.

Diener, C. I., \& Dweck, C. S. (1978). Analysis of learned helplessness - continuous changes in performance, strategy, and achievement cognitions following failure. Journal of Personality and Social Psychology, 36(5), 451-462. https://doi.org/10.1037/0022-3514.36.5.451.

Dignath, C., \& Buttner, G. (2008). Components of fostering self-regulated learning among students. A metaanalysis on intervention studies at primary and secondary school level. Metacognition and Learning, 3(3), 231-264. https://doi.org/10.1007/s11409-008-9029-x.

Dresel, M., \& Ziegler, A. (2006). Langfristige Förderung von Fähigkeitsselbstkonzept und impliziter Fähigkeitstheorie durch computerbasiertes attributionales Feedback. Zeitschrift Fur Padagogische Psychologie, 20(1/2), 49-63. https://doi.org/10.1024/1010-0652.20.12.49.

Dresel, M., Schober, B., Ziegler, A., Grassinger, R., \& Steuer, G. (2013). Affektiv-motivational adaptive und handlungsadaptive Reaktionen auf Fehler im Lernprozess. Zeitschrift Fur Padagogische Psychologie, 27(4), 255-271. https://doi.org/10.1024/1010-0652/A000111.

Dupeyrat, C., \& Mariné, C. (2005). Implicit theories of intelligence, goal orientation, cognitive engagement, and achievement: A test of Dweck's model with returning to school adults. Contemporary Educational Psychology, 30(1), 43-59. https://doi.org/10.1016/j.cedpsych.2004.01.007.

Dweck, C. S. (2008). Mindset: The new psychology of success (paperback ed.). New York: Random House.

Dweck, C. S. (2017). The journey to children's mindsets - and beyond. Child Development Perspectives, 11(2), 139-144. https://doi.org/10.1111/cdep.12225. 
Dweck, C. S., \& Leggett, E. (1988). A social-cognitive approach to motivation and personality. Psychological Review, 95(2), 256-273. https://doi.org/10.1037//0033-295x.95.2.256.

Eccles, J. S., \& Wigfield, A. (2002). Motivational beliefs, values, and goals. Annual Review of Psychology, 53(1), 109-132. https://doi.org/10.1146/annurev.psych.53.100901.135153.

EDK The Swiss Conference of Cantonal Ministers of Education (2017). Bildungssystem Schweiz. http://www. edk.ch/dyn/14798.php. Accessed 10 April 2018.

Fryer, J. W., \& Elliot, A. J. (2007). Stability and change in achievement goals. Journal of Educational Psychology, 99(4), 700-714. https://doi.org/10.1037/0022-0663.99.4.700.

Gardner, D. G., Cummings, L. L., Dunham, R. B., \& Pierce, J. L. (1998). Single-item versus multiple item measure: An empirical comparison. Educational and Psychological Measurement, 58(6), 898-915. https://doi.org/10.1177/0013164498058006003.

Garner, J. K. (2009). Conceptualizing the relations between executive functions and self-regulated learning. The Journal of Psychology, 143(4), 405-426. https://doi.org/10.3200/JRLP.143.4.405-426.

Gestsdottir, S., von Suchodoletz, A., Wanless, S. B., Hubert, B., Guimard, P., Birgisdottir, F., Gunzenhauser, C., \& McClelland, M. (2014). Early behavioral self-regulation, academic achievement, and gender: Longitudinal findings from France, Germany, and Iceland. Applied Developmental Science, 18(2), 90-109. https://doi.org/10.1080/10888691.2014.894870.

Gunderson, E. A., Gripshover, S. J., Romero, C., Dweck, C. S., Goldin-Meadow, S., \& Levine, S. C. (2013). Parent praise to 1 - to 3-year-olds predicts children's motivational frameworks 5 years later. Child Development, 84(5), 1526-1541. https://doi.org/10.1111/cdev.12064.

Gunderson, E. A., Sorhagen, N. S., Gripshover, S. J., Dweck, C. S., Goldin-Meadow, S., \& Levine, S. C. (2018). Parent praise to toddlers predicts fourth grade academic achievement via children's incremental mindsets. Developmental Psychology, 54(3), 397-409. https://doi.org/10.1037 /dev0000444.

Haimovitz, K., \& Dweck, C. S. (2017a). Corrigendum: "what predicts children's fixed and growth intelligence mind-sets? Not their parents' views of intelligence but their parents' views of failure" (Psychological Science, 27 (6), 859-869, 2016). Psychological Science, 28(4), 551. https://doi.org/10.1177 $/ 0956797617697952$.

Haimovitz, K., \& Dweck, C. S. (2017b). The origins of Children's growth and fixed mindsets: New research and a new proposal. Child Development, 88(6), 1849-1859. https://doi.org/10.1111/cdev.12955.

Hasselhorn, M. (2005). Lernen im Altersbereich zwischen 4 und 8 Jahren: Individuelle Voraussetzungen, Entwicklung, Diagnostik und Förderung. In T. Guldimann \& B. Hauser (Eds.), Bildung 4- bis 8-jähriger Kinder (pp. 77-88). Münster: Waxman.

Hauser, B. (2013). Spielen: Frühes Lernen in Familie, Krippe und Kindergarten (Entwicklung und Bildung in der frühen Kindheit). Stuttgart, Germany: Kohlhammer.

Hong, Y. Y., Chiu, C. Y., Dweck, C. S., Lin, D. M. S., \& Wan, W. (1999). Implicit theories, attributions, and coping: A meaning system approach. Journal of Personality and Social Psychology, 77(3), 588-599. https://doi.org/10.1037//0022-3514.77.3.588.

$\mathrm{Hu}$, L. t., \& Bentler, P. M. (1999). Cutoff criteria for fit indexes in covariance structure analysis: Conventional criteria versus new alternatives. Structural Equation Modeling: A Multidisciplinary Journal, 6(1), 1-55. https://doi.org/10.1080/10705519909540118.

Kamins, M. L., \& Dweck, C. (1999). Person versus process praise and criticism: Implications for contingent selfworth and coping. Developmental Psychology, 35(3), 835-847. https://doi.org/10.1037/0012-1649.35.3.835.

Kinlaw, C. R., \& Kurtz-Costes, B. (2007). Children's theories of intelligence: Beliefs, goals, and motivation in the elementary years. The Journal of General Psychology, 134(3), 295-311. https://doi.org/10.3200/GENP.134.3.295-312.

Kline, R. B. (2011). Principles and practice of structural equation modeling (3rd ed., methodology in the social sciences). New York: Guilford Press.

Kubesch, S., \& Hinte, S. (2014). Exekutive Funktionen und Selbstregulation: Neurowissenschaftliche Grundlagen und Transfer in die pädagogische Praxis. Bern, Switzerland: Huber.

Lipko, A. R., Dunlosky, J., Lipowski, S. L., \& Merriman, W. E. (2012). Young children are not Underconfident with practice: The benefit of ignoring a fallible memory heuristic. Journal of Cognition and Development, 13(2), 174-188. https://doi.org/10.1080/15248372.2011.577760.

Mangels, J. A., Butterfield, B., Lamb, J., Good, C., \& Dweck, C. S. (2006). Why do beliefs about intelligence influence learning success? A social cognitive neuroscience model. Social Cognitive and Affective Neuroscience, 1(2), 75-86. https://doi.org/10.1093/scan/ns1013.

Marsh, H. W., Ellis, L. A., \& Craven, R. G. (2002). How do preschool children feel about themselves? Unraveling measurement and multidimensional self-concept structure. Developmental Psychology, 38(3), 376-393. https://doi.org/10.1037//0012-1649.38.3.376. 
McClelland, M. M., Cameron, C. E., Connor, C. M., Farris, C. L., Jewkes, A. M., \& Morrison, F. J. (2007). Links between behavioral regulation and preschoolers' literacy, vocabulary, and math skills. Developmental Psychology, 43(4), 947-959. https://doi.org/10.1037/0012-1649.43.4.947.

McClelland, M. M., Cameron, C. E., Duncan, R., Bowles, R. P., Acock, A. C., Miao, A., \& Pratt, M. E. (2014). Predictors of early growth in academic achievement: The head-toes-knees-shoulders task. Frontiers in Psychology, 5, 599. https://doi.org/10.3389/fpsyg.2014.00599.

Measelle, J., Ablow, J., Cowan, P., \& Cowan, C. (1998). Assessing young Children's views of their academic, social, and emotional lives: An evaluation of the self-perception scales of the Berkeley puppet interview. Child Development, 69(6), 1556-1576.

Moffitt, T. E., Poulton, R., \& Caspi, A. (2013). Lifelong impact of early self-control childhood self-discipline predicts adult quality of life. American Scientist, 101(5), 352-359. https://doi.org/10.1511/2013.104.352.

Moriguchi, Y., \& Hiraki, K. (2013). Prefrontal cortex and executive function in young children: A review of NIRS studies. Frontiers in Human Neuroscience, 7, 867. https://doi.org/10.3389/fnhum.2013.00867.

Mueller, C. M., \& Dweck, C. S. (1998). Praise for intelligence can undermine children's motivation and performance. Journal of Personality and Social Psychology, 75(1), 33-52. https://doi.org/10.1037//00223514.75.1.33.

Muthén, L. K., \& Muthén, B. O. (1998-2016). Mplus user's guide statistical analysis with latent variables (5th ed.). Los Angeles: Muthen.

Neuenschwander, R., Rothlisberger, M., Cimeli, P., \& Roebers, C. M. (2012). How do different aspects of selfregulation predict successful adaptation to school? Journal of Experimental Child Psychology, 113(3), 353371. https://doi.org/10.1016/j.jecp.2012.07.004.

Nicholls, J. G. (1978). The development of the concepts of effort and ability, perception of academic attainment, and the understanding that difficult tasks require more ability. Child Development, 49(3), 800-814.

Panadero, E. (2017). A review of self-regulated learning: Six models and four directions for research. Frontiers in Psychology, 8, 422. https://doi.org/10.3389/fpsyg.2017.00422.

Park, D., Gunderson, E. A., Tsukayama, E., Levine, S. C., \& Beilock, S. L. (2016). Young Children's motivational frameworks and math achievement: Relation to teacher-reported instructional practices, but not teacher theory of intelligence. Journal of Educational Psychology, 108(3), 300-313. https://doi. org/10.1037/edu0000064.

Paunesku, D., Walton, G. M., Romero, C., Smith, E. N., Yeager, D. S., \& Dweck, C. S. (2015). Mind-set interventions are a scalable treatment for academic underachievement. Psychological Science, 26(6), 1-10. https://doi.org/10.1177/0956797615571017.

Raines-Eudy, R. (2000). Using structural equation modeling to test for differential reliability and validity: An empirical demonstration. Structural Equation Modeling: A Multidisciplinary Journal, 7(1), 124-141. https://doi.org/10.1207/s15328007sem0701_07.

Rattan, A., Good, C., \& Dweck, C. S. (2012). "It's ok - not everyone can be good at math": Instructors with an entity theory comfort (and demotivate) students. Journal of Experimental Social Psychology, 48(3), 731737. https://doi.org/10.1016/j.jesp.2011.12.012.

Raver, C. C., Carter, J. S., McCoy, D. C., Roy, A., Ursache, A., \& Friedman, A. (2012). Testing models of children's self-regulation within educational contexts: Implications for measurement. Advances in Child Development and Behavior, 42, 245-270. https://doi.org/10.1016/B978-0-12-394388-0.00007-1.

Robins, R. W., \& Pals, J. L. (2002). Implicit self-theories in the academic domain: Implications for goal orientation, attributions, affect, and self-esteem change. Self and Identity, 1(4), 313-336. https://doi. org/10.1080/15298860290106805.

Röthlisberger, M., Neuenschwander, R., Michel, E., \& Roebers, C. M. (2010). Exekutive Funktionen: Zugrundeliegende kognitive Prozesse und deren Korrelate bei Kindern im späten Vorschulalter. Zeitschrift Fur Entwicklungspsychologie und Pädagogische Psychologie, 42(2), 99-110. https://doi.org/10.1026/0049$8637 / \mathrm{a} 000010$.

Satorra, A., \& Bentler, P. M. (2010). Ensuring positiveness of the scaled difference chi-square test statistic. Psychometrika, 75(2), 243-248. https://doi.org/10.1007/S11336-009-9135-Y.

Schermelleh-Engel, K., Moosburger, H., \& Müller, H. (2003). Evaluating the fit of structural equation models: Tests of significance and goodness-of-fit models. Methods of Psychological Research Online, 8, 23-74.

Schloz, C., \& Dresel, M. (2011). Implizite Fähigkeitstheorien und Fähigkeitsselbstkonzepte im Grundschulalter. In F. Hellmich (Ed.), Selbstkonzepte im Grundschulalter: Modelle, empirische Ergebnisse, pädagogische Konsequenzen (pp. 81-99). Stuttgart, Germany: Kohlhammer.

Schroder, H. S., Fisher, M. E., Lin, Y., Lo, S. L., Danovitch, J. H., \& Moser, J. S. (2017). Neural evidence for enhanced attention to mistakes among school-aged children with a growth mindset. Developmental Cognitive Neuroscience, 24, 42-50. https://doi.org/10.1016/j.den.2017.01.004. 
Sektnan, M., McClelland, M. M., Acock, A., \& Morrison, F. J. (2010). Relations between early family risk, children's behavioral regulation, and academic achievement. Early Childhood Research Quarterly, 25(4), 464 479. https://doi.org/10.1016/j.ecresq.2010.02.005.

Sisk, V. F., Burgoyne, A. P., Sun, J. Z., Butler, J. L., \& Macnamara, B. N. (2018). To what extent and under which circumstances are growth mind-sets important to academic achievement? Two meta-analyses. Psychological Science, 29(4), 549-571. https://doi.org/10.1177/0956797617739704.

Smiley, P. A., \& Dweck, C. S. (1994). Individual differences in achievement goals among young children. Child Development, 65(6), 1723-1743. https://doi.org/10.1111/j.1467-8624.1994.tb00845.x.

Spinath, B. (2001). Implizite Theorien über die Veränderbarkeit von Intelligenz und Begabung als Bedingungen von Motivation und Leistung. Lengerich: Dissertation, Universität Bielefeld, Pabst Science Publ.

Spinath, B., \& Freiberger, V. (2011). Implizite Theorien und Selbstkonzepte. In F. Hellmich (Ed.), Selbstkonzepte im Grundschulalter: Modelle, empirische Ergebnisse, pädagogische Konsequenzen (pp. 100-116). Stuttgart: Kohlhammer.

Stipek, D., \& Gralinski, J. H. (1996). Children's beliefs about intelligence and school performance. Journal of Educational Psychology, 88(3), 397-407. https://doi.org/10.1037/0022-0663.88.3.397.

Ursache, A., Blair, C., \& Raver, C. C. (2012). The promotion of self-regulation as a means of enhancing school readiness and early achievement in children at risk for school failure. Child Development Perspectives, 6(2), 122-128. https://doi.org/10.1111/j.1750-8606.2011.00209.x.

Vernon-Feagans, L., Willoughby, M., Garrett-Peters, P., \& Investigators, F. L. P. K. (2016). Predictors of behavioral regulation in kindergarten: Household chaos, parenting, and early executive functions. Developmental Psychology, 52(3), 430-441. https://doi.org/10.1037/dev0000087.

Vohs, K. D., Baumeister, R. F., \& Schmeichel, B. J. (2012). Motivation, personal beliefs, and limited resources all contribute to self-control. Journal of Experimental Social Psychology, 48(4), 943-947. https://doi. org/10.1016/j.jesp.2012.03.002.

von Suchodoletz, A., Gawrilow, C., Gunzenhauser, C., Merkt, J., Hasselhorn, M., Wanless, S. B., et al. (2014). Erfassung der Selbstregulation vor dem Schuleintritt. Psychologie in Erziehung und Unterricht, 61(3), 165174. https://doi.org/10.2378/peu2014.art13d.

Willoughby, M. T., Blair, C. B., \& Investigators, F. L. P. K. (2016). Measuring executive function in early childhood: A case for formative measurement. Psychological Assessement, 28(3), 319-330. https://doi. org/10.1037/pas0000152.

Zimmerman, B. J. (1989). A social cognitive view of self-regulated academic learning. Journal of Educational Psychology, 81(3), 329-339. https://doi.org/10.1037/0022-0663.81.3.329.

Zimmerman, B. J., \& Kitsantas, A. (2014). Comparing students' self-discipline and self-regulation measures and their prediction of academic achievement. Contemporary Educational Psychology, 39(2), 145-155. https://doi.org/10.1016/j.cedpsych.2014.03.004.

Publisher's note Springer Nature remains neutral with regard to jurisdictional claims in published maps and institutional affiliations. 